\title{
"Now We Are All in the Same Boat. At the Same Time, We Are Not." Meaning-Making and Coping Under COVID-19 Lockdown in Norway
}

\author{
Ella Marie Sandbakken ${ }^{1} \cdot$ Sigrun Marie Moss ${ }^{2}$
}

Received: 31 October 2020 / Revised: 5 March 2021 / Accepted: 22 March 2021

(c) The Author(s), under exclusive licence to Springer Nature Switzerland AG 2021, corrected publication 2021

\begin{abstract}
On March 12, 2020, Norway went on lockdown to handle the COVID-19 outbreak. Near overnight, people faced a new and unfamiliar situation, with restrictive measures in place, extensive uncertainty and the closing down of much of society. The present study explores the meaning-making and coping in everyday life of 16 participants interviewed early in the pandemic. Norway, compared to many other settings in the world, is a privileged context. Nonetheless, participants struggled with this breach with their normal lives. The participants spoke of adapting to the new normal, how the concept of time had changed, how they handled socialisation, dealing with restricted freedom, and imagining the future. Actively drawing on communal coping, as well as problem-focused and emotion-focused individual coping strategies, participants' accounts illustrate the on-going process of making meaning of their new lives under lockdown. In our discussion, we synthesise various coping processes that the participants made use of in their handling of the new situation. Even though the COVID-19 pandemic is a shared stressor, it influences people differently, and our research contributes with valuable insights into this variation. The recognition of different meaning-making and coping strategies is crucial, as it can constructively inform the development of political and social responses to the pandemic that actively encompasses the variation in individual experiences and ramifications.
\end{abstract}

Keywords COVID-19 · Meaning-making · Individual coping · Communal coping · Qualitative research · Norway

Ella Marie Sandbakken

ella.sandbakken@bhioslo.no

Sigrun Marie Moss

s.m.moss@psykologi.uio.no

1 Department of Psychology, Bjørknes University College, Oslo, Norway

2 Department of Psychology, University of Oslo, Oslo, Norway 


\section{Introduction}

I feel like that Thursday [12 March 2020] - the 'Hoarding Thursday' - was a turning point. That was when the government stepped in. (...) The measures were quite intrusive, and they came so fast. And people had to readjust so incredibly quickly to a new daily life. (...) That hoarding week went from being like, 'oh, yeah, corona is just a bit of cough, Jesus Christ, we have to be able to live our lives' to being, 'this is completely...' Suddenly, like snapping your fingers, you realised how serious and lifechanging this was to become. (Participant I)

In the first period of the COVID-19 pandemic, many societies went on lockdown to gain control of the virus spread. This was also the case for Norway. On 12 March 2020, the Norwegian government implemented the most restrictive measures the country had experienced in peacetime. This lockdown included closing kindergartens, schools, and universities (Government, 2020). Home office was strongly encouraged, travel restrictions were put in place, and most leisure actives, the night-scene, sports initiatives, and art scene events were closed down. Social distancing was imposed: in private homes, gatherings could not exceed five people, and people were to keep a minimum of 2 metres apart from others than those in their household. Although many other countries faced stricter restrictions (for example Italy, Spain, South Africa, and China), the change from the Norwegian status quo to lockdown was drastic.

In our paper, through a thematic analysis of in-depth interviews with individuals in differing life situations, we investigate the following research question: how did participants in this early phase make meaning of their new everyday lives and how did they cope with living in lockdown? Studies have shown increased psychological distress during early phases of the COVID-19 pandemic (Johnson et al., 2020; Qiu et al., 2020; Rossi et al., 2020; Xiong et al., 2020), making it important to explore how individuals made sense of and coped with the changed life during the first lockdown. Our analysis of these participants' meaning-making processes and coping strategies contributes with valuable insights on how varied these processes can be for individuals. The results suggest that development of social and political responses to collective stressors, such as pandemics, needs to acknowledge the variation in the impact of the stressor, as well as in people's meaningmaking and coping with the situation in question.

\section{The Norwegian Setting}

Context is crucial when investigating how individuals handle the COVID-19 pandemic (Jetten et al., 2021). Norway is a welfare state, characterised by a certain redistribution of income through high taxes to pay for inclusive welfare structures, as well as an extensive public sector (Simon \& Mobek, 2019). This structure ensures access to social welfare services for people, regardless of income. Norway also has the largest sovereign wealth fund in the world and is thus economically well-placed to handle the pandemic. For example, during the first lockdown, the Norwegian government set in place economic support systems for people being laid off work, for artists whose livelihood disappeared with the closed art scene, for parents who had to be away from work (with the schools and kindergartens closed), and so forth. 
According to Project GLOBE's (Global leadership and organisational behaviour effectiveness) study (House et al., 2004), Norway scores 4.8 (band A, high) in the Humane Orientation, which includes that people are urged to provide social support for each other (see Warner-Søderholm, 2012). For example, engaging in "dugnad" (voluntary communal work) is a well-known feature of Norwegian social life, which is frequently tied to the welfare state (Lorentzen \& Dugstad, 2011). Norway is also a high-trust society, which has been important in the handling of the current pandemic, as this context seems to facilitate general population compliance to governmental measures (Christensen \& Lægreid, 2020; Moss \& Sandbakken, 2021; Van Bavel et al., 2020). In the annual trust survey conducted in Norway in November 2020, trust in the Norwegian Parliament rose from 76 to 87\%, reaching historically high levels. The survey press release states: "This may be a sign that the population in times of crisis will stand by the societal institutions" (Aftenposten, 5 January 2021). Furthermore, Norway has been characterised as a "tight" culture when it comes to social norms, defined as adhering to strict norms and having limited tolerance for norm deviation (Gelfand et al., 2011). The classification of cultures on a continuum from "tight" to "loose" has been raised by Van Bavel et al. (2020) and Gelfand et al. (2021) as relevant for handling the COVID-19 pandemic. They suggest that it may be easier for tight cultures to enforce the regulations and rules needed to fight the virus. The cultural context, with its world-views, social norms, and expectations, is likely to influence coping and meaningmaking during this pandemic (Guan et al., 2020).

\section{Meaning-Making and Coping: A Variational Approach}

As emphasised by Van Bavel et al. (2020), the COVID-19 situation is likely experienced as a major stressor for most people, and individuals differ in how they cope with the stressful situation. Making meaning of our daily lives serves different functions, including attempting to control the uncontrollable (Josephs \& Valsiner, 1998). "In many ways, human reasoning in everyday contexts is a miracle. We are capable of making up our mind - as well as changing it instantly - about different aspects of our present relation to the environment" (Josephs \& Valsiner, 1998, p. 68). We here look at constructions of meaning as created, recreated and used in people's immediate context. Changing everyday life events require altered meaning-making, which is carried out in relation to the flexibilities and rigidities of the context (Josephs \& Valsiner, 1998). In this, the context is key, but it is the person who has the agency. That said, meaning is created and co-created, and we thus ascribe to a view where the self is made up of dialoguing with the internalised voices of others (see Bakhtin, 1981; Josephs \& Valsiner, 1998). That is, the voices of those present, but also those relevant to the person albeit distant in time and space (Bakhtin, 1986). These voices thus "come into being as a relation between person and culture" (König, 2009, p. 102).

The pandemic was new and unknown territory, and the co-creation of meaning was an ongoing negotiation for our participants. Needing to control the uncontrollable, meaningmaking is particularly acute in such situations. In this study, we explore how people coped with the new situation, drawing on the literature on individual coping and communal coping, whilst acknowledging and emphasising variation to understand such phenomena (Adams, 2012; Valsiner, 1984). 


\section{Individual Coping}

A stressor of unknown duration or which occurs unexpectedly in the individual's life could increase the likelihood of the situation being appraised as stressful and affect how the individual perceives its own ability to cope with the stressor (Compas et al., 1991; Lazarus \& Folkman, 1984; Main et al., 2011). The COVID-19 situation is therefore likely to be appraised as a stressor by many individuals, having occurred unexpectedly, with large ramifications for people's everyday life and without having a clear "end point."

Stress can be managed with different strategies, and people often use multiple coping strategies (Lazarus \& Folkman, 1984). Problem-focused coping strategies are characterised by the individual attempting to alter the stressful situation. Such strategies include planning, active coping, problem solving, and assertive confrontation (Lazarus \& Folkman, 1984; Zimmer-Gembeck \& Skinner, 2011). Emotion-focused coping strategies, on the other hand, consist of individuals not confronting the stressful situation directly, but instead using strategies to handle own emotional responses to the stressor (Lazarus \& Folkman, 1984). Such strategies include changing appraisals of the situation, avoidance or acceptance, positive comparisons, or positive reinterpretations (Chew et al., 2020).

\section{Communal Coping}

Communal coping is often defined as a community or groups of people tackling a common stressor together (Lyons et al., 1988). Communal coping differs from individual coping and also from social support, on appraisal, and action dimensions (Lyons et al., 1998). The first dimension relates to whether one is experiencing the same stressor and collectively seeing it as a shared problem. The second dimension is to what degree the problem is constructed as a shared responsibility to tackle, with shared efforts to handle the stressor (see also Afifi et al., 2006). Several studies find that such communal coping can lead to reductions in uncertainty. This reduction of uncertainty allows for greater sense of resilience, efficacy, and security (see Afifi et al., 2012; Bonanno et al., 2007). Afifi et al. (2012) underline that communal coping should be particularly valuable for alleviating the stress of uncertainty following disasters or difficult circumstances, by offering trust that the group of people can handle the event together.

Placing these coping strategies - both individual and communal-within the variational mode of thinking (Valsiner, 1984), we are actively looking for and recognising the heterogeneity in the phenomena, instead of searching for homogenised averages, as is the focus of a typological mode of thinking (Valsiner, 2017). Valsiner (1984) emphasises both synchronic variability (between individuals) as well as diachronic variability (within the individual), and the variational mode of thinking seeks to explore and get at a fuller range of experiences. This focus on variation is linked to an emphasis on instability and changing nature of the world rather than the portrayal of constancy. If one exclusively focused on the latter, "the changing nature of these phenomena can easily remain unattended to" (Valsiner, 1984, p. 451). The pandemic has thrown people into new and fast changing circumstances, and this variational mode of thinking is a fitting framework for our discussion of coping and meaning-making during this first lockdown period. 


\section{Methodology}

In early April 2020, we wished to explore the meaning-making and coping that individuals in this early phase engaged in to handle their new everyday lives. To investigate this topic, we conducted qualitative in-depth interviews, which would provide insights into different people's experiences of the COVID-19 situation. Our research was approved by the Norwegian Centre for Research Data (NSD). We reached out in our broad networks and used snowball sampling to recruit eight participants each $(N=16)$. Conducting acquaintance interviews (Garton \& Copland, 2010) can be especially suitable when researching individual meaning-making, as it may facilitate rapport (Braun \& Clarke, 2013) and make interview participants open up more (Blichfeldt \& Heldbjerg, 2011). However, we were aware that in such interviews, the researcher enters a dual relationship with the participant (that of both acquaintance and researcher), which requires ethical considerations (Braun \& Clarke, 2013). Following recommendations from Braun and Clarke (2013), we discussed our roles with the participants and specifically explained that only the interview material would be used for analysis. To avoid feelings of obligation to participate in the study, we made it clear that we had invited many more than we needed. Six people declined the invitation.

The interview sample consists of 16 individuals in diverse life situations: 8 females and 8 males, ages ranging from early 20s to early 70s. Eleven of the participants were employed, two had lost their jobs because of the situation, two were retired, five were in "high-risk" groups, three were health professionals, seven worked at home offices due to the pandemic, three had small children at home, and one lived alone. Hence, our sample consists of a range of life situations and circumstances, which allows for varied insights into how everyday life was managed by people being differently affected by the measures (in line with Valsiner's variational mode of thinking, 1984). However, all but two participants were at the centre/left on the political scale.

Both researchers conducted eight semi-structured in-depth interviews each between 5 and 23 April. This period was still characterised by widespread uncertainty and extensive restrictions on individual lives. We followed the same pre-made interview guide (see Appendix). All interviews were conducted in Norwegian. Four of the interviews were done in person, six via phone, and six on Zoom. The interviews lasted from 25-78 minutes. All interviews were recorded. Each researcher transcribed her own interviews verbatim in full, anonymising the interviews in the transcription process.

Regarding reflexivity, we are both Norwegian and lived in Norway during the lockdown period. Our insider positions provided valuable insights into the context but could also lead to a lack of distance. Even though we are both in privileged positions-neither of us lost our jobs nor were in other ways financially affected by the restrictions-we were as everyone else personally affected by the lockdown situation. The first author was suddenly working from home and experienced multiple cancellations of personal significance. The second author was also working from home, whilst caring for small children as the kindergarten was closed. While the first author had an increase in time to fill, the second author experienced having less time. This way, like our participants, we were affected by the situation in different ways, helping us understand and appreciate the participants' different accounts better (Braun \& Clarke, 2013, 2019). 


\section{Analysis and Results}

We conducted an inductive thematic analysis (Braun \& Clarke, 2006, 2013) of the interview data, adhering to the reflexive thematic analysis approach (Braun \& Clarke, 2019). Both authors read and reread the material. As we were curious about the coping strategies and the meaning-making processes the participants engaged in during this uncertain lockdown period, we noted the extensive parts of the interviews that spoke to this. Using selective coding (Braun \& Clarke, 2013), we collaboratively coded interview material relevant to our research question. We systematically structured the coded material into broad categories, which we developed through reflecting on and discussing recurring patterns in the data material. We reworked these categories several times, as we kept generating first initial—and later finalised — themes. Throughout this process, we were reflexive in our approach (see Braun \& Clarke, 2019), relating carefully and thoughtfully to the material, our roles in the processes, and our own embeddedness in the pandemic.

Within our social constructionist epistemological approach to the material, all the accounts are seen as valid but subjective, and as constructed through the participants' ongoing meaning-making processes and constructions of the situation (Burr, 2015). In line with this framework, we acknowledge the themes as co-created through our interactions with the participants and with the data material. We adopt the starting point that peoples' life environment and personality are interdependent and that the phenomena in question are best understood by "the whole range of variation" in experiences, emotions and behaviours (Valsiner, 1984, p. 461). Keen to get at such variation, we have mapped out the extensive variation of the meaning-making and coping that the participants engaged in. This allows for breadth in the material, but it also limits the depth of the analysis. However, as emphasised by Braun and Clarke (2013), such a mapping can contribute valuable knowledge. In our reading, we actively looked for and explored both the individual and the communal positions that the participants evoked in their accounts.

Our analysis resulted in our construction of five themes (and ten subthemes): (1) adapting to an everyday life in lockdown, (2) a matter of time, (3) handling changed socialising, (4) relatively restricted freedom, and (5) imagining the future (see Table 1 for thematic map, with short example quotes). Combined, these tell the overarching story of how the 16 participants made meaning of and coped with the lockdown situation, illustrating the variation in experiences of the initial COVID-19 lockdown.

\section{Theme 1: Adapting to an Everyday Life in Lockdown}

When the strict COVID-19 measures were imposed by the Norwegian government, the population had to quickly adapt to a new daily life: "On Monday certain things were advised against. Tuesday it was strongly advised against. And on Thursday it all shut down" (Participant C). Not expecting the drastic turn of events, many participants spoke of the lockdown situation coming abruptly. Everyday life as the participants knew it had changed drastically in a very short period of time, and they had to reconstruct their lives to a life in lockdown. Even though seemingly the whole society was "in the same boat," participants still pointed out how the pandemic and lockdown hit different groups differently, seeing individual context as important for how the new everyday life was handled. 


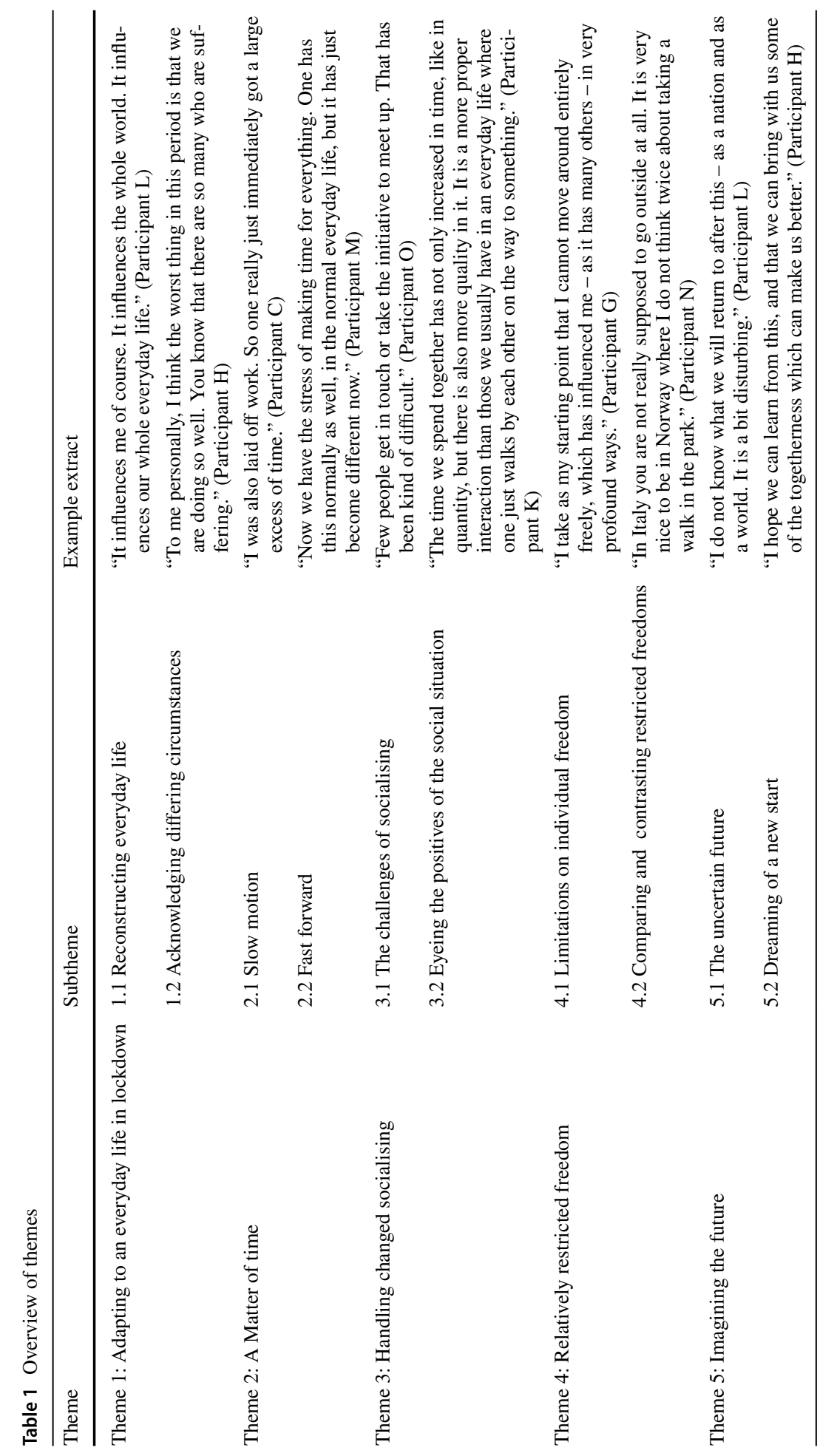




\section{Reconstructing Everyday Life}

The turning point of 12 March marked the beginning of a new life situation, and the participants discussed their processes of constructing a new everyday life in this chaotic period. A few did not experience massive changes in their daily rhythm, but for most participants, the pandemic did alter their everyday life extensively. For some, this meant taking action to figure out how to manage the new life situation:

In the beginning, it was very much like, 'how are we going to do this?' And we had thoughts and different set-ups for everything, and then we tested the ground and after a while one sees what works and not. Now, after three weeks, we have started to get things more on track, making everyday life run a bit more smoothly. (Participant M)

Participant $\mathrm{M}$ had to adjust to both home office and home-schooling for his children. As his quote shows, he and his family actively dealt with the new situation, figuring out practical solutions. However, the COVID-19 situation is characterised by uncertainty and sudden changes. Sudden stressful events interfered with active coping and could disrupt adjustment to this new everyday life:

I am not a huge fan of changes. When all this happened, I no longer had the usual rhythm of getting up, catching the bus, going to work, and so on. (...) It took a few weeks - two or three weeks - before I managed to fully settle down. And when I began coming to terms with the situation, my wife got temporarily laid off. And then that became a change as well. So, I have spent some mental capacity on getting used to new routines, in a way. (Participant L)

The external stressors were out of the participants' control, and the changes were sudden, making the situation unpredictable. This seemed to complicate coping with the stressors and the process of adjusting to a "new normal." Participants also stressed that individuals differed in how they experienced the situation: "Whereas my husband finds it more exciting, following all developments closely and watching the news all the time, I might get more tired of the uncertainty of the situation" (Participant B). While participants L and B described spending a lot of mental capacity on adapting and finding the changes stressful, others described a more positive view of their own handling of the altered life situation:

We try to go for a walk in the morning before work so that we sort of 'walk to work.' It is very nice! And we try as best we can to limit the working hours versus the time off, so we have all our job things in the big living room, and then when we are done, we close that door, and then it is okay to keep it closed off until the next day. That has actually worked very well! (Participant G)

Unlike participant G, participant C had been laid off work due to the pandemic. Still, like participant $\mathrm{G}$, participant $\mathrm{C}$ structured his days in a manner that mimicked his normal pre-COVID-19 schedule: "I have made a rather planned everyday life for myself, so that I have goals for my everyday life (...). So that I get things done, even if there is not much to do." Participant C explained that his everyday life in the lockdown had gotten better after he started living by a more normal—but self-constructed—schedule. This was not mainly to get things done, but to maintain structure.

Having to figure out how to reconstruct everyday life to life in lockdown, many participants actively engaged in finding practical solutions or creating new habits that helped 
normalise the non-normal situation. This process seemed to be experienced very differently, with some participants finding the changes more difficult than others.

\section{Acknowledging Differing Circumstances}

Even though many participants talked extensively of how everyone was in the same situation, many also stressed how the pandemic hit people differently: "Now we are all in the same boat. At the same time, we are not, because some of us are let off frightfully easy, whereas health workers and such are in it with both feet" (Participant H). This awareness of how practical circumstances differed extensively was echoed by several other participants: "I have friends who have been temporarily laid off work, and friends who are managers who have had to temporarily lay off all their employees. They do not sleep and are having a very hard time" (Participant $\mathbf{J}$ ).

In addition to some people being hit harder by the pandemic (health workers, people laid off work), others experienced the "new normal" as challenging because this was already their "old normal":

To me personally it is a bit unpleasant with the very supportive, "poor people who are stuck at home.' Think of all of us who have that as our life situation, and who do not see any end to it. (...) If you are chronically ill, you get criticising looks if you manage to go to the shop or to work. They think we are having a blast and have a perfect situation where we are sitting at home being ill. Now everyone is saying, 'how are we going to get through this dreadful time, it is so hard for us!' My God, it will be a year at most, or 18 months before they find a vaccine. I do not feel sorry for you. (Participant E)

The participant's everyday situation, which she felt others viewed as the perfect set-up (leeching off of the national welfare system), was suddenly portrayed as the hardest thing to cope with: "poor people stuck at home." This participant's account puts into perspective how the situation and the portrayal of it as a major stressor could be experienced by someone whose "old normal" overlapped with the "new normal" due to chronic illness. Explaining it further, she also stated that people now had solidarity with all the people stuck at home, but that this did not extend to the chronically ill.

\section{Theme 2: A Matter of Time}

With society closing down, many participants experienced suddenly living their everyday lives in slow motion, since they had gotten extra time they actively had to fill. Others, on the other hand, described the opposite: they were in life situations that made time a scarce resource as their lives became more hectic than usual, and their everyday lives were on fast forward. In other words, the concept of time and how this changed with the lockdown situation was largely emphasised in the interviews, but the way experiences of time had changed varied in line with life situation. Hence, the interviews showed variation and contrasts in individual experiences, illustrating how differently the same lockdown could influence people's lives. 


\section{Slow Motion}

With all events cancelled, social distancing imposed, and most activities closed, many participants experienced their general everyday lives filled with a lot of extra time:

I notice that generally it feels a bit like things are on hold, because even though I physically leave the house for work, I know that every day I am going home, and my schedule after four o'clock is empty. (Participant K)

This sudden slowing down of the pace of everyday life was by some participants described as positive, making their lives less stressful and providing them with unexpected extra time to do things they had wanted to do for a long time. Some had finally read books, painted their houses, or gotten around to projects they had put off for years. One of the participants explained: "Now I can concentrate fully on my own self-development, and that is actually very long-awaited (...) To be specific, I have now read one big, important book that I put on hold for 10-15 years."

Others had found activities to fill their time with to deal with the changes, like going for walks, doing puzzles, baking, watching movies, or playing games. For these participants, time was something they had to fill: "We have more time we have to fill now, because a lot of these ordinary things we usually went to are not there anymore. I hope they will return, but they are not happening now" (Participant A). While some participants found these new activities both pleasant and meaningful, others explicitly emphasised the unwantedness of the situation:

The situation I am living in now is like a kind of... summer vacation. Where you sort of do not have any plans and all your friends are away. Mostly I am just home, because you cannot meet people and I do not really have anywhere to go. I cannot go to school, I cannot go to work, so I am at home studying and exercising. I sort of miss having a schedule, which I did not think that I would. I hate routines, but apparently, I enjoy routines very much. (Participant C)

This account is one of time almost standing still, with the COVID-19 situation slowing down time in an unwanted way. The participant described how he managed to fill time by constructing a new schedule for himself. This, he said, was important, as it was exhausting to do nothing for too long.

These participants' accounts of actively filling time, stands in stark contrast to those participants who experienced the opposite: getting less time in the lockdown due to work situations or suddenly having small children at home.

\section{Fast Forward}

A few of the participants, particularly those with jobs that experienced an upsurge under the crisis (for example health workers) and those with small children (as child-care and schools were closed), said that time became a scarcity, more so than before. Participant D, a mother of young children, explained: "It has been family life on speed! (...) For 24 hours a day you have a baby plus a toddler, so there was a point when I was afraid I was going to go nuts because it is so demanding." Participant D spoke about the strain of the situation, with her husband working, and herself being home with both kids as the kindergarten was closed: 
If you are on parental leave with little children you seldom have time to yourself, and now it is an extreme lack of it. The other day I got to write an e-mail, I think I was on the toilet writing an e-mail. I almost started to cry, I was so happy to be doing something completely different, something that was about me.

This account speaks to the lockdown period as taking time away, due to the added pressure on parents having children at home. Participant $\mathrm{M}$ was in a similar life situation, also having small children at home school while working from home. He described the strains on his time making him worry whether he was doing enough at work and enough for his children, stating that: "Now everything is left halfway, right?".

A participant who was in a life situation where he had gotten a lot of extra time, which he enjoyed, got a reality check on how others were not necessarily in the same situation as him when reaching out to a colleague:

I called a colleague that I keep in touch with, and said, 'I'm sitting here and all of a sudden I have a lot of spare time, so I thought it would be nice to catch up.' And he said, 'wow, really, you have a lot of time?' Then he told me that, 'I'm sorry, I'd love to catch up, but not now. Because, you see, my wife is a nurse, I'm a labour union representative, and my children...' He has small children, and has to try to get them through their school days. 'So I'm sorry.' And then I realised that I have to be humble here - realise where I am. (Participant P)

It again became clear how differently the pandemic hit different groups, showing the variation of individual experiences. Participants' concept of time had changed, but in contrasting ways depending on life situation: some had to cope with time suddenly being (even more of) a scarcity, while others had to adjust to a sudden surplus of time.

\section{Theme 3: Handling Changed Socialising}

A key aspect changed by the lockdown was how people could interact with others. Participants spoke about the challenges of interacting with few people. Some also described feeling isolated, and that the aspects that they were missing the most were social gatherings, like meeting friends and family. Participants also emphasised positive aspects of the changed social situation. Some spoke of digital socialisation and the societal feeling of being in this together as ways of easing the changed socialising, while others described quality interactions with the few people with whom they socialised.

\section{The Challenges of Socialising}

Most participants described various challenges with the changed social aspect of their lives. Many spoke of missing others. Participant H, a grandmother, said: "We miss grandchildren, and being able to hug others." When asked if digital contact helped when he missed social interaction, participant $\mathrm{M}$ answered:

It helps, absolutely. It does. But there is something about being with people. Laughing, and... Yes. Going out after work one day and having a beer with some buddies and sitting around chatting, or going to somebody else's place to play PlayStation, or [laughs] whatever, right? These are the small things you miss.

A challenge of changed socialising was the feeling of isolation and loneliness. This was particularly the case for participants who, due to different circumstances, did not have 
established networks already. Being new at a job or new in town put one in a more vulnerable situation when it came to socialising:

My partner and I have been trying to get in touch with other colleagues. But we have sort of experienced that less people answer when we reach out, and that people might already have planned to meet three or four people. And then we cannot join as well. (...) In a way we have not been included. But that is because there are restrictions regarding how many who can be together. (Participant $\mathrm{O}$ )

Other people already had a group of friends that reached the limit for how many were allowed to meet up, making the restrictions directly limiting this participant's possibility of being included by others.

While some participants described increased distance to others as difficult, others emphasised a lack of distance, since the restrictions led to people spending a lot more time with the ones they lived with. Speaking of her partner, participant K said: "I think when you are that close all the time, conflicts can arise... We have not argued that much, but you notice that you can get more annoyed, or, I notice that I can get more annoyed by little things." Participants generally recognised the advantage of living with someone rather than alone, but a few, like participant K, emphasised that it could be too close at times-particularly for those living in small flats.

\section{Eyeing the Positives of the Social Situation}

The lockdown situation had made many participants realise how important social interactions and relationships were to them. For instance, participant A explained how social contact with others was different than before because it was suddenly a scarcity: "We are so rarely together with other people now, so when we are, I think we show each other that we are very happy to be together - that we appreciate that being together is now almost like a luxury." Echoing the words of participant A, many others spoke about the improved quality in their social interactions and relations, as these were more limited, fewer, and far between.

Many also acknowledged that living with someone was an advantage in the situation, and several described the increased time with the ones they lived with as a positive outcome of the lockdown situation:

The time you spend together [with the family] has been very nice, now that we have had to come up with things to do, and done more things together that we enjoy, you know? Every evening now we have game night with board games, or we read more books. It is very cosy. It is actually good quality time. (Participant $\mathrm{M}$ )

This sentiment was echoed by participant D, who emphasised the positive aspect of increased family time: "Family life on speed - I did actually get to know my daughter better, who would normally spend much of her time in kindergarten. This was for better and for worse, goddamn. But you get to know each other better." Hence, even though feeling the strains on their time with small children at home, both participant $\mathrm{M}$ and $\mathrm{D}$ also described increased family time as a positive aspect of the situation, showing variation and internal contrast within the participants' own experiences. That said, several participants also acknowledged that the lockdown must have been much more challenging for people in difficult domestic situations. The awareness of others' hardship was frequently mentioned, 
and participants seemed to be more grateful for their own situations when engaging in such comparisons.

In addition to spending more time with a few people, most participants explained how they kept in touch with friends or family by phone or video calls. Some participants (for example I, G, and C) described how they now had more contact than before the lockdown with some people, through digital platforms: "Now in this period, I am seeing some people more than I ever have [laughs]" (Participant L). Actively socialising online by meeting friends or family for online quizzes, gaming, movie nights, or having drinks, was by several participants described as positive experiences: "With some colleagues from work we meet [on Zoom] every Friday afternoon. (...) It is very, very nice to be able to hang out together, and it lasts a couple of hours. It is great. It is very good!" (Participant G). The participant also praised how his workplace took time to meet digitally every morning:

With work we have meetings every day at 9 am, for 5-10 minutes, but it is so good to see people because... The faces of my colleagues are sort of my everyday life. Like, if I were to give my everyday life a face, it would be theirs and that of my partner. So just having their faces pop up on the screen has actually been very important, and maybe more important than usual. (Participant G)

Hence, digital socialisation was by several participants presented as an active way of coping with the limited real-life social interactions, and by many described as a positive experience.

Some participants emphasised not only increased closeness with people they lived with or through digital communication but also feeling closer to the society at large, making isolation easier to handle: "People [in the society] sort of stick together and that creates a kind of sense of unity, that we will manage this because we take care of each other. I have personally felt that nice, good, warm feeling" (Participant I). The sense of unity seemed for several participants to ease meaning-making of why physical distancing was important: to take care of the community as a whole. Others emphasised that individuals were now making personal sacrifices for the "greater good" of the community and for others:

A lot of people - not me - are making huge sacrifices by being temporarily laid off, their economy is going to hell, they cannot visit old people, grandchildren, a whole lot of things like that, people are doing things for others and for the community. (Participant F)

The general sense of unity, and the emphasis on togetherness and solidarity, was described as a positive outcome of the COVID 19-situation. Several participants said this sense of unity made it easier to adjust to a more socially isolated everyday life, and some stressed that this overarching sense of community was more present than before the lockdown.

\section{Theme 4: Relatively Restricted Freedom}

A direct consequence of the Norwegian government's measures was restrictions on individual freedom. The participants emphasised these restrictions as limiting individual freedom and changing their everyday lives, but also recognised the freedom the Norwegian measures still allowed for, especially when comparing to and contrasting with countries with stricter restrictions. 


\section{Limitations on Individual Freedom}

In the participants' everyday lives, there were suddenly limitations on what they could do, both due to restrictions and to cancellations: "I attend a language course. It has been cancelled. I take a course at the local college. It has been cancelled. I have an art venue subscription. It has been cancelled. So, there is nothing to do" (Participant A).

Being in a global state of emergency was by many participants stated as a reason for accepting individual sacrifices and restrictions. For instance, a participant made meaning of restrictions affecting personally significant events by pointing to the global situation:

It might have been more challenging to move our wedding if there had not been something global, something beyond our control. It is something we do not have power over that decided that we had to move it. And then it is easier to accept it, I think.

There was, however, variation in how easy participants felt it was to accept restrictions on individual freedom. Participant L emphasised how the limitations of his freedom to do whatever he wanted was something he accepted but also felt a resistance to:

Not meeting family, friends... Not being able to travel where you want. Not being outside much. For instance, I cannot go and work out at the gym. Not that it is a critical matter, because I do not spend much time there anyway [laughs], but still... Knowing that you cannot, even if I might not have used it, there is something about having it restricted which is always a difficult situation. I probably get a bit childish, thinking, 'yes, but I want to, so why not?' But like I said, it is alright anyway. I manage to see the greater good and that it is worth it.

Even though feeling resistance to restrictions on his freedom, participant $\mathrm{L}$ accepted the restrictions by making meaning of them as necessary. This meaning-making process was expressed also by other participants, who stated that cancellations could feel difficult on a personal level, but that cancellations and restrictions were necessary for the greater good of the society. This emphasis on collectively handling the pandemic seemed to make restrictions on individual freedom easier to accept.

\section{Comparing and Contrasting Restricted Freedoms}

When comparing or contrasting the Norwegian lockdown situation with that of other countries, many participants seemed to find it easier to accept restrictions on their own lives. Participants focused on how lucky they felt to be in Norway whilst going through this period, compared to being in other countries, empathising with the plights of other areas affected more severely:

Because we both have an international family and international friends, we become very aware of all the magnificent things we have in Norway, with nature and playgrounds and a healthcare system and a government you can trust. I know that it will be alright, and that is very nice - knowing that we are going to manage. Compared to lots of others who do not have that trust. I think about that a lot, that we are still very lucky in that regard. (Participant D) 
The freedom to move around, be outside, go to the forest, and for the children to play outside were recurrent topics emphasised as easing handling of the situation, and participants emphasised the privileged situation of having enough space.

Hence, participants were aware of their freedom only being partly restricted in the global context of the pandemic. When talking of being home with small children, for example, and frustrating over certain closed playgrounds and the likes, the participants who had children would often also reflect on not being in Spain where one was required to spend all day indoors. Similarly, participants would talk about leisure activities being closed, but then emphasising that one could still at least use the woods and have other activities in nature: "I can still go out, I can go to the park" (participant $\mathrm{N})$. Hence, knowledge of the measures being less restrictive than those in other countries seemed to make it easier to cope with the restricted situation.

\section{Theme 5: Imagining the Future}

Participants described diverse and varied views on the future. Some participants expressed concern about how the future would turn out and described fear of economic collapses or struggles, losing loved ones to the virus, or not being able to return to a normal life. Here, the large degree of uncertainty and not knowing how the situation would turn out and for how long it would last, was described as particularly distressing. Others, on the other hand, emphasised how the COVID-19 situation disrupting status quo was an opportunity to rethink the set up and workings of society, and a possibility for reframing life. This way, a new and better future could be possible.

\section{The Uncertain Future}

The COVID-19 situation is largely characterised by uncertainty. Indeed, many participants mentioned worrying about different outcomes:

I am worried about the situation and the people I love. And I am worried that we do not really know the outcome of this. It is so uncertain where this is going. There are so many experts saying different things. (...) I am definitely worried. I notice that I am a bit uneasy, a bit tired - more than I might have acknowledged. I notice that the more time passes, the more tiresome it gets. (Participant B)

Not knowing the outcomes and the likelihood of the different possible outcomes seemed particularly worrisome for participant B, who described the uncertainty as tiring. Such worry was also shared by some other participants, who described spending a lot of mental capacity on imagining different scenarios: "They are saying that a lot of people in Norway will be infected with corona. Will it be alright? For how long will things be closed? Will people lose their jobs?" (Participant M).

While many worried about the outcomes of both the virus and the lockdown, others described the stressfulness of not knowing how long the situation would last:

The thought of this potentially lasting a year has been a bit claustrophobic at times. That it is like, 'will I not be able to go out and have a beer with friends? Will I never be allowed to dance in a club? Is this what life has been reduced to?' sort of. (Participant I) 
Some participants described being detached or distancing themselves from the situation to avoid being distressed by the uncertainty: "I am a bit detached from a lot of things. I do not have the energy to take it all in. (...) We are living through such an enormous experiment. I am a bit worried about that" (Participant J). While participant $\mathrm{J}$ described being detached and avoiding thinking too much about the uncertain future, other participants spent a lot of time worrying and imagining scenarios. Some participants, however, saw a potential new start arising from the pandemic.

\section{Dreaming of a New Start}

COVID-19 turned many people's lives upside down, disrupting the status quo that is usually taken for granted in busy everyday lives. Some participants saw this disruption as an opportunity - the opportunity to rethink what really matters and what kind of society is desirable:

Hopefully something good can come from this situation, that we do not forget it as soon as this is over, but that we actually have gotten a wake-up call as to what values we want in a society. (...) I think it has become a very existential time. (Participant H)

Other participants shared this positive outlook on how the situation hopefully had taught people that they were more able to contribute to changes if these are done together: "I hope that we can (...) learn that we are actually very dependent on each other and that everyone has to do their bit" (Participant D).

A couple of participants specifically connected learning from the shared handling of the pandemic to ways of dealing with the climate crisis. Even as they were describing hope and optimism considering the possibility of a new start, some participants also stated that enduring a change in lifestyle could be difficult:

People are flying a lot less now, and people are staying at home, so now we are polluting less. That is the place we need to get to. But what is everybody talking about? And even I am sitting here talking about it: That the economy will suffer so much that a lot of people will have a hard time. So, we are trapped. (Participant P)

However, participant $\mathrm{P}$ also hoped - as did some other participants - that some changes would endure when people noticed that they were able to adapt to them. Especially, it was stressed that air traffic could potentially be reduced when people now noticed both that work meetings could be done through video calls, and that local holidays could replace some travels abroad:

We are discovering that it is wonderful to walk along the Oslo-fjord, you do not have to go to the Mediterranean to lie on a beach. It is not a human right to get tanned in the winter. (...) There is much greater humility now, and that might be one of the best things about this. (Participant P)

Hence, participants balanced hope and fear for future outcomes in their meaning-making of how the pandemic could affect the world and their own lives. While some participants were worrying about loved ones, the economy, and for how long the situation would last, others were making meaning of the crisis by reframing it as providing a possibility to give new insights into what really matters, and possibly enabling a new start. 


\section{Discussion}

When everyday life is changed abruptly, individuals try to make sense of the situation (Crossley, 2000). Many of our participants described the lockdown situation as changing their lives drastically. The turning point of 12 March was described as what Walsh (2020) has named "loss of normalcy" in the pandemic, where "people had to readjust so incredibly quickly to a new daily life" (Participant I, Theme 1). This adjustment process to a "new normal" was experienced differently by different participants. Our participants told us their stories of how they made meaning of and coped with this early national lockdown to control the spread of COVID-19 in Norway. Participants described how they coped with the sudden change in their everyday lives (Theme 1), how the concept of time had changed (Theme 2), handling changed socialising (Theme 3), and dealing with restricted individual freedom (Theme 4). The participants also spoke of the future, related to uncertainty and worry, but also to hope and dreams of new beginnings (Theme 5). In our discussion, we explore and synthesise the participants' meaning-making of their new lives through different coping strategies: individual coping (Lazarus \& Folkman, 1984) and communal coping (Lyons et al., 1998).

\section{Individual Coping}

Van Bavel et al. (2020) underline that it is not the type or amount of stress that determines how the COVID-19 pandemic will impact an individual-rather, it is dependent on the situational appraisals of the stressful situation (Lazarus \& Folkman, 1984). Indeed, the participants in our study described different experiences of the pandemic and engaged in both problem-focused and emotion-focused coping strategies to manage their new everyday lives.

\section{Problem-Focused Coping Strategies}

Simply changing the stressful situation is not an option in a global pandemic (Van Bavel et al., 2020). However, problem-focused coping strategies are still possible, both with regard to following measures that can prevent virus spread (Cheng \& Cheung, 2005; Chew et al., 2020; McCauley et al., 2013), like complying with and making sense of wearing face masks (Tateo, 2020), as well as actively coping with everyday life issues in a more restricted situation (Young et al., 2020).

Theme 1 showed how participants had to reconstruct their everyday lives. Many described actively seeking solutions to practical changes, constructing a new life that had some routines similar to their pre-lockdown lives. Confronting the stressors of change and uncertainty by creating a structured life was described positively by the participants, making it easier to cope with the changes. This was also illustrated in theme 2 , where participants who suddenly had gotten extra time actively filled this time with projects and pleasant activities. When facing the stressors of social distancing and isolation, which likely would harden coping during a pandemic (Van Bavel et al., 2020), almost all participants had made active use of phoning others more or engaging in digital forms of communication, as shown in theme 3 . 
Such problem-focused approaches to cope with the COVID-19 pandemic—establishing a new daily routine or finding new hobbies and spending time outdoors - has by quantitative research been associated with lower levels of anxiety and depressive symptoms and more successful adaptation to the situation (Fullana et al., 2020). These types of problem-focused coping strategies with the COVID-19 pandemic have also been associated with better handling of the stressor than emotion-focused strategies (Fu et al., 2020; Yang, 2021). Even though many of our participants actively handled the situation by using problem-focused coping strategies of avoiding virus spread, planning and actively taking charge of their new everyday lives, participants also seemed to apply several emotion-focused coping strategies.

\section{Emotion-Focused Coping Strategies}

In emotion-focused coping strategies, the individual does not confront the stressful situation directly, but cope with own emotional reactions to the stressor through strategies such as altering appraisals of the situation, avoiding or accepting it, or conducting positive comparisons or reinterpretations (Lazarus \& Folkman, 1984). Participants seemed to implement several of these strategies to reduce negative emotions. Especially, the emotion-focused coping strategy of positive reinterpretations was described by several participants. When time slowed down (Theme 2), some participants described it as an opportunity to do things one had put off for a long time and finally live a less stressful life. Such positive reinterpretations also seemed to influence social aspects (Theme 3), where many participants described the few social interactions they had as being good quality time. As Van Bavel et al. (2020) put it, stressful situations can "help reorganize our priorities and can help lead to deeper relationships and a greater appreciation for life" (p. 467). This seemed to be the case for those participants in our study who viewed the pandemic as an opportunity to rethink societal values and priorities (Theme 5). Similar experiences have been described in previous qualitative research on nurses coping with the SARS epidemic, where interview participants spoke of appreciating their relationships, health, and everyday life more than before the epidemic (Mok et al., 2005).

Another emotion-focused coping strategy used was that of making positive comparisons, which could replace negative emotions with gratitude. For instance, participants made positive comparisons to others in less privileged positions, like those who were living alone (Theme 3), or to countries with stricter measures (Theme 4). In addition, the emotion-focused coping strategy of avoidance was described by some participants, who stated being detached and not wanting to take in the situation. The fact that many participants were filling their time (Theme 2) with activities could also be an expression of the emotion-focused coping strategy of distracting oneself from the situation, which has also been suggested in previous research on coping in the SARS epidemic (Chan et al., 2007), the Ebola epidemic (Rabelo et al., 2016), and the COVID-19 pandemic (Fu et al., 2020). 


\section{Communal Coping}

There are several coping strategies in the pandemic that have at its core a sentiment that is at the root of communal coping, namely that a stressor is "our problem and our responsibility" (Afifi et al., 2006, p. 378). As emphasised by Jetten et al. (2021, p. 2) "because of the contagious nature of COVID-19, it is not just 'my' behaviour that matters, but the behaviour of all of 'us"'. External threats, such as natural disasters, are commonly found to make people come together (Greenaway \& Cruwys, 2019). Coping is constructed together by people experiencing similar stressful events. This allows the community to make meaning of the events together and see the solution as a shared undertaking.

One could ask whether the strict social distancing measures in place, with restrictions as to how many one could meet, would have impeded communal coping. However, from our participants' accounts, particularly in theme 3, this did not seem to be the case. Rather, it seems that the overarching sense of being in this together, as well as finding ways of socialising despite the measures, fostered a sense of communal coping for many.

\section{A Shared Fate?}

The first dimension of communal coping relates to whether people see the stressor as a shared, communal stressor (Lyons et al., 1998). The stressor-the virus situation-was spoken of as something that everyone was experiencing, and several participants explicitly stated that the overarching sense of community was more present than before the pandemic (Theme 3). This fits well with other findings on epidemic crises, which have shown individually experienced positive outcomes, like increased sense of community, care, empathy, altruistic behaviours, and concern for others (Chew et al., 2020; Li, 2020). Similarly, Sibley et al. (2020), comparing a pre-lockdown and post-lockdown sample in New Zealand, found among other aspects a stronger sense of patriotism and national identification in the postlockdown sample.

Indeed, in the participants' narratives, the "shared boat" image was frequently invoked. Even so, there was also a large degree of awareness amongst our participants that the pandemic hits different people differently, and this extensive variation was mentioned frequently. However, Lyons et al. (1998, p. 583) emphasise that such different consequences do not stand in the way of communal coping: "Regardless of whether the stressor produces similar consequences for all, communal coping involves thinking and acting as if a stressor is shared." Indeed, participants in our sample frequently spoke of a sense of being in the situation together, and seemed to appraise the stressor as a shared, communal stressor.

\section{A Communal Handling of the Stressor?}

The second dimension of communal coping relates to the degree in which the problem is constructed as owned by individuals or the group (Lyons et al., 1998; see also Afifi et al., 2006). This involves action directed at handling the stressor in question, related to both the 
needs of oneself and those of others in the community (Lawrence \& Schigelone, 2002). In the context of our participants, there was a societal narrative of the COVID situation as an issue requiring collective handling, with the government using the Norwegian concept of dugnad in their communication, which speaks to voluntary community work (Moss \& Sandbakken, 2021). Trying to handle the stressor communally was by many of our participants put forth as a motivation that made challenging restrictions more meaningful, which made it easier to adjust to the new everyday life. This sense of togetherness and unity was linked to making meaning of specific actions to handle the pandemic, as a way to care for the community as a whole. However, due to strict social distancing measures, the communal efforts of handling the stressor differed from other emergencies, such as natural disasters. Everyone knew that all relied on everyone's contribution to halt the spread of the virus, but the social distancing may have influenced the sense of communality and thus the motivation to contribute. Still, one can imagine that the internalised social voices of others (Bakhtin, 1981) will influence one's take on the situation, as will the rigidities and boundaries for appropriate behaviour in the context influence meaning-making and behaviours (see Josephs $\&$ Valsiner, 1998). However, there is reason to question whether some persons may be left out of this communal coping narrative on the action dimension. For example, vulnerable groups were presented as the ones to be protected, and were thus potentially less actively included in the narrative of handling the stressor. Here, it is also important to emphasise that different groups in society may be in situations that complicate contributing to the shared action. For example, social distancing could be made difficult by densely populated areas or multi-generational housing, as well as low-socioeconomic individuals less able to selfisolate and work from home (see Atchison et al., 2020; Jetten, 2020; Templeton et al., 2020).

Lastly, for several participants the action-related aspect did not stop with the pandemic. Experiencing the pandemic as a shared problem, and the need for a shared solution, enabled visions for future avenues of communal handling of shared stressors, such as the climate crisis (Theme 5). Participant H called it "a very existential time," and a few participants hoped for a future where people collaborated more actively to handle challenges together.

\section{Limitations and Further Research}

When it comes to coping and meaning-making it should be emphasised that our sample contained 5 people who were from the "at risk" groups related to COVID-19, but only a few in our sample had suffered harsh, direct consequences of the lockdown (two lost their jobs; one lost care services related to chronic illness). That our sample is fortunate compared to many others, both within Norway and not least in comparison to other contexts, needs to be acknowledged. However, understanding the participants' coping and meaningmaking of a radical shift in their everyday lives is valuable, as it provides insights into how unexpected stressors can be subjectively experienced, made sense of, and coped with.

Further research could investigate temporal aspects of coping with a pandemic. Do individual coping strategies change over time? Is a sense of communal coping retained, or does 
it fade? (See for example Elgizouli et al., in press). In addition, it should be investigated how people in other contexts cope with and make meaning of everyday life under COVID19 lockdowns. Norway is characterised as a tight culture (Gelfand et al., 2011), and a relatively interdependent welfare-state-hence exploring other types of settings would enable getting at more variation, as emphasised by Valsiner (1984). Finally, further research could look at how meaning-making and coping is managed when a country returns to a new lockdown during the COVID-19 pandemic, and whether coping and meaning-making would be different the second or third time around.

\section{Making Meaning of and Coping With New Daily Lives}

Concluding, we see that both individual and communal coping seemed to be important coping strategies used by our participants in their handling of their new everyday lives. However, the interdependency embedded in communal coping seemed to be evoked by the participants as an overarching meaning-making framework for the situation; the stressor was shared and should be handled together. Many participants spoke warmly about a sense of unity and togetherness, which seemed to ease both meaning-making of and compliance with the restrictions (see also Moss \& Sandbakken, 2021). However, participants also emphasised that the lockdown affected people differently, related to consequences for people's lives, how they experienced it, how they coped with it, and made meaning of it. The material demonstrates the synchronic variation between people-for example, people enjoying the slower pace versus people struggling with the added demands on their time. The material also shows the diachronic variation within people-for example the very same people who were struggling with having their children at home on top of their work demands, simultaneously appreciated this time with their family (see Valsiner, 1984).

Even within a relatively homogenous culture, such as Norway, where many experienced being in the same boat as others in this lockdown, there was extensive variation in both meaning-making and coping. The article at large thus speaks volumes to the importance of the variational mode of thinking when mapping out meaning-making and coping under this pandemic. If one had looked for more typological answers (Valsiner, 1984), such variations on the psychological phenomena in question would have been lost. To increase understanding of such phenomena is crucial when a lengthy pandemic takes its toll as people strive to handle radical changes and stressors in their everyday lives.

Our research suggests that when politicians initiate political and social responses to the pandemic, it is important that they acknowledge and incorporate this dual focus on both the variation of people's situations and their individual and communal coping. Acknowledging this variation will similarly be important for different institutions and health workers, handling the longer-term effects of the pandemic. Finally, it is important that people in general also realise that others are facing different ramifications of the COVID-19 situation, as well as acknowledging that people cope differently with this pandemic-even though the stressor is shared. 


\section{Appendix}

\section{Interview guide}

- Gender, age, profession?

- General:

- How has the Corona-virus affected you?

- Negative aspects?

- Any positive aspects?

- Your situation right now:

- Are you home or at work?

○ Do you live with others?

- If yes, how has it been if you are spending much time at home with others? Positives/negatives?

- If no, do you feel isolated? In what ways?

- Are you connecting with others (either if you are alone, or outside of your household)?

- How?

- Is the contact and way of contact different from how you would normally interact with others?

- Government approach?

- What is the government approach?

- What are the rules or measures taken?

- How are these articulated? As rules or recommendations?

- How are these measures influencing everyday life for you?

- Do you agree with the measures?

- Are they over-reacting? Are these right? Are they too soft?

- Rules:

- How do you feel about the measures or rules?

- Do people in general feel it is important to follow the rules?

- Is there any negative backlash from self or others for breaking the rules?

- Do people police each other with regards to these rules?

- Worry:

○ Do you worry about the situation?

- How? What do you worry about?

- What are you most worried about? What are you least worried about?

- Are there things you know others worry about that you do not worry about?

- Previous hardship:

- Have you lived through crises before? Are there any similarities between that and this?

- Are there any other aspects you wish to mention, that we have not covered in the interview?

- Thank you for your time!

Acknowledgements We want to thank our participants, who set aside time for us to interview them in a challenging time. We also want to thank the reviewers for constructive comments on our paper, as well as Christian Palacios Haugestad, Anja Duun Skauge, Therese Hjellnes, and Synne Kjelling Skagseth for insightful and valuable feedback on earlier versions of this paper. From the same interview study, we have 
published one earlier article (Political Psychology) on government meta-narratives and interview participants' reactions to these (see Moss \& Sandbakken, 2021). In the present study, other parts of the interview material were used to explore variation in individual meaning-making and coping.

\section{References}

Adams, G. (2012). Context in person, person in context: A cultural psychology approach to social-personality psychology. In K. Deaux \& M. Snyder (Eds.), The Oxford handbook of personality and social psychology. (pp. 182-208). Oxford University Press.

Afifi, W. A., Felix, E. D., \& Afifi, T. D. (2012). The impact of uncertainty and communal coping on mental health following natural disasters. Anxiety, Stress \& Coping, 25(3), 329-347. https://doi.org/10.1080/ 10615806.2011.603048

Afifi, T. D., Hutchinson, S., \& Krouse, S. (2006). Toward a theoretical model of communal coping in postdivorce families and other naturally occurring groups. Communication Theory, 16(3), 378-409. https:// doi.org/10.1111/j.1468-2885.2006.00275.x

Aftenposten. (2021). Topp tiltro til myndighetene under koronapandemien. (Great trust in authorities under the corona pandemic). Aftenposten. Retrieved from Aftenposten.no

Atchison, C. J., Bowman, L., Vrinten, C., Redd, R., Pristera, P., Eaton, J. W., \& Ward, H. (2020). Perceptions and behavioural responses of the general public during the covid-19 pandemic: A cross-sectional survey of UK adults. MedRxiv. https://doi.org/10.1101/2020.04.01.20050039

Bakhtin, M. M. (1981). The dialogic imagination (C. Emerson \& M. Holquist, trans.). Austin: University of Texas Press.

Bakhtin, M. M. (1986). Speech genres and other late essays (V. W. McGee, Trans.). Austin: University of Texas Press.

Blichfeldt, B. S. \& Heldbjerg, G. (2011). Why not? The interviewing of friends and acquaintances. Working paper 2011/1. Aalborg University: Department of Entrepreneurship and Relationship Management.

Bonanno, G. A., Galea, S., Bucciarelli, A., \& Vlahov, D. (2007). What predicts psychological resilience after disaster? The role of demographics, resources, and life stress. Journal of Consulting and Clinical Psychology, 75, 671-682. https://doi.org/10.1037/0022-006X.75.5.671

Braun, V., \& Clarke, V. (2006). Using thematic analysis in psychology. Qualitative Research in Psychology, 3(2), 77-101. https://doi.org/10.1191/1478088706qp063oa

Braun, V., \& Clarke, V. (2013). Successful qualitative research: A practical guide for beginners. Sage Publications Ltd.

Braun, V., \& Clarke, V. (2019). Reflecting on reflexive thematic analysis. Qualitative Research in Sport, Exercise and Health, 11(4), 589-597. https://doi.org/10.1080/2159676X.2019.1628806

Burr, V. (2015). Social constructionism. (3rd ed.). Routledge.

Chan, S. S., Leung, D., Chui, H., Tiwari, A. F., Wong, E. M., Wong, D. C., \& Lau, Y. L. (2007). Parental response to child's isolation during the SARS outbreak. Ambulatory Pediatrics, 7(5), 401-404. https:// doi.org/10.1016/j.ambp.2007.06.002

Cheng, C., \& Cheung, M. W. (2005). Psychological responses to outbreak of severe acute respiratory syndrome: A prospective, multiple time-point study. Journal of Personality, 73(1), 261-285. https://doi. org/10.1111/j.1467-6494.2004.00310.x

Chew, Q. H., Wei, K. C., Vasoo, S., Chua, H. C., \& Sim, K. (2020). Narrative synthesis of psychological and coping responses towards emerging infectious disease outbreaks in the general population: Practical considerations for the COVID-19 pandemic. Tropical Journal of Pharmaceutical Research, 61(7), 350-356. https://doi.org/10.11622/smedj.2020046

Christensen, T. \& Lægreid, P. (2020). Balancing governance capacity and legitimacy. How the Norwegian government handled the COVID-19 crisis as a high performer. Public Administration Review, 80(5), 774-779. https://doi.org/10.1111/puar.13241

Compas, B. E., Banez, G. A., Malcarne, V., \& Worsham, N. (1991). Perceived control and coping with stress: A developmental perspective. Journal of Social Issues, 47(4), 23-34. https://doi.org/10.1111/j. 1540-4560.1991.tb01832.x

Crossley, M. L. (2000). Narrative psychology, trauma and the study of self/identity. Theory \& Psychology, 10(4), 527-546. https://doi.org/10.1177/0959354300104005

Elgizouli, U. K., Hussain, A., \& Moss, S. M. (in press). "Chanting at 1 pm Revolution time." Collective action as communal coping in Sudan. In W. Lopez \& L. Taylor (Eds.) Transitioning to Peace: Contributions of peace psychology around the world. Springer Peace Psychology Series. Cham: Springer Nature 
Fu, W., Wang, C., Zou, L., Guo, Y., Lu, Z., Yan, S., \& Mao, J. (2020). Psychological health, sleep quality, and coping styles to stress facing the COVID-19 in Wuhan China. Translational Psychiatry, 10(1), 1-9. https://doi.org/10.1038/s41398-020-00913-3

Fullana, M. A., Hidalgo-Mazzei, D., Vieta, E., \& Radua, J. (2020). Coping behaviors associated with decreased anxiety and depressive symptoms during the COVID-19 pandemic and lockdown. Journal of Affective Disorders, 275, 80-81. https://doi.org/10.1016/j.jad.2020.06.027

Garton, S., \& Copland, F. (2010). 'I like this interview; I get cakes and cats!': The effect of prior relationships on interview talk. Qualitative Research, 10(5), 533-551. https://doi.org/10.1177/14687 94110375231

Gelfand, M. J., Jackson, J. C., Pan, X., Nau, D., Pieper, D., Denison, E., \& Wang, M. (2021). The relationship between cultural tightness-looseness and COVID-19 cases and deaths: A global analysis. The Lancet Planetary Health. https://doi.org/10.1016/S2542-5196(20)30301-6

Gelfand, M. J., Raver, J. L., Nishii, L., Leslie, L. M., Lun, J., Lim, B. C., \& Aycan, Z. (2011). Differences between tight and loose cultures: A 33-nation study. Science, 332, 1100-1104. https://doi. org/10.1126/science. 1197754

Government no. (2020). Coronavirus measures to continue [Press release 55/20]. Retrieved from https:// www.regjeringen.no/en/aktuelt/coronavirus-measures-to-continue/id2694682/

Greenaway, K. H., \& Cruwys, T. (2019). The source model of group threat: Responding to internal and external threats. American Psychologist, 74(2), 218-231. https://doi.org/10.1037/amp0000321

Guan, Y., Deng, H., \& Zhou, X. (2020). Understanding the impact of the COVID-19 pandemic on career development: Insights from cultural psychology. Journal of Vocational Behavior, 119. https://doi. org/10.1016/j.jvb.2020.103438

House, R. J., Hanges, P. J., Javidan, M., Dorfman, P. W., \& Gupta, V. (Eds.). (2004). Culture, leadership, and organizations: The GLOBE study of 62 societies. Sage publications.

Jetten, J. (2020). Inequality, in J. Jetten, S. D. Reicher, S. A. Haslam \& T. Cruwys (Eds.), Together Apart. The Psychology of COVID-19 (pp. 101-106). London: SAGE.

Jetten, J., Bentley, S. V., Crimston, C. R., Selvanathan, H. P., \& Haslam, S. A. (2021). COVID-19 and social psychological research: A silver lining. Asian Journal of Social Psychology. https://doi.org/ 10.1111/ajsp. 12465

Johnson, S. U., Ebrahimi, O. V., \& Hoffart, A. (2020). PTSD symptoms among health workers and public service providers during the COVID-19 outbreak. PloS One, 15(10). https://doi.org/10.1371/ journal.pone.0241032

Josephs, I. E., \& Valsiner, J. (1998). How does autodialogue work? Miracles of meaning maintenance and circumvention strategies. Social Psychology Quarterly, 61(1), 68-82. https://doi.org/10.2307/ 2787058

König, J. (2009). Moving experience: Dialogues between personal cultural positions. Culture \& Psychology, 15(1), 97-119. https://doi.org/10.1177/1354067X08099617

Lawrence, A. R., \& Schigelone, A. R. S. (2002). Reciprocity beyond dyadic relationships: Aging-related communal coping. Research on Aging, 24(6), 684-704. https://doi.org/10.1177/016402702237187

Lazarus, R. S., \& Folkman, S. (1984). Stress, appraisal, and coping. Springer.

Li, A. C. M. (2020). Living through COVID-19: A perspective from Hong Kong. Journal of Humanistic Psychology, 60(5), 672-681. https://doi.org/10.1177/0022167820938487

Lorentzen, H. \& Dugstad, L. (2011). Den norske dugnaden: Historie, kultur og fellesskap. Kristiansand; Norway: Høyskoleforlaget.

Lyons, R. F., Mickelson, K. D., Sullivan, M. J. L., \& Coyne, J. C. (1998). Coping as a communal process. Journal of Social and Personal Relationships, 15(5), 579-607. https://doi.org/10.1177/ 0265407598155001

Main, A., Zhou, Q., Ma, Y., Luecken, L. J., \& Liu, X. (2011). Relations of SARS-related stressors and coping to Chinese college students' psychological adjustment during the 2003 Beijing SARS epidemic. Journal of Counselling Psychology, 58(3), 410-423. https://doi.org/10.1037/a0023632

McCauley, M., Minsky, S., \& Viswanath, K. (2013). The H1N1 pandemic: Media frames, stigmatization and coping. BMC Public Health, 13(1), 1116. https://doi.org/10.1186/1471-2458-13-1116

Mok, E., Chung, B. P., Chung, J. W., \& Wong, T. K. (2005). An exploratory study of nurses suffering from severe acute respiratory syndrome (SARS). International Journal of Nursing Practice, 11(4), 150-160. https://doi.org/10.1111/j.1440-172X.2005.00520.x

Moss, S. M. \& Sandbakken, E. M. (2021). "Everybody needs to do their part, so we can get this under control." Reactions to the Norwegian government meta-narratives on COVID-19 measures. Advance online publication. Political Psychology. https://doi.org/10.1111/pops.12727 
Qiu, J., Shen, B., Zhao, M., Wang, Z., Xie, B., \& Xu, Y. (2020). A nationwide survey of psychological distress among Chinese people in the COVID-19 epidemic: implications and policy recommendations. General psychiatry, 33(2). https://doi.org/10.1136/gpsych-2020-100213

Rabelo, I., Lee, V., Fallah, M. P., Massaquoi, M., Evlampidou, I., Crestani, R., \& Severy, N. (2016). Psychological distress among ebola survivors discharged from an ebola treatment unit in Monrovia, Liberia-A qualitative study. Frontiers in Public Health, 4, 142. https://doi.org/10.3389/fpubh. 2016.00142

Rossi, R., Socci, V., Talevi, D., Mensi, S., Niolu, C., Pacitti, F., \& Di Lorenzo, G. (2020). COVID-19 pandemic and lockdown measures impact on mental health among the general population in Italy. Frontiers in Psychiatry, 11, 790. https://doi.org/10.3389/fpsyt.2020.00790

Sibley, C. G., Greaves, L. M., Satherley, N., Wilson, M. S., Overall, N. C., Lee, C. H. J., \& Barlow, F. K. (2020). Effects of the COVID-19 pandemic and nationwide lockdown on trust, attitudes toward government, and well-being. American Psychologist, 75(5), 618-630. https://doi.org/10.1037/ amp0000662

Simon, C., \& Mobekk, H. (2019). Dugnad: A fact and a narrative of Norwegian prosocial behaviour. Perspectives on Behavior Science, 42(4), 815-834. https://doi.org/10.1007/s40614-019-00227-w

Tateo, L. (2020). Face masks as layers of meaning in times of COVID-19. Culture \& Psychology, Advance Online Publication. https://doi.org/10.1177/1354067X20957549

Templeton, A., Guven, S. T., Hoerst, C., Vestergren, S., Davidson, L., Ballentyne, S., \& Choudhury, S. (2020). Inequalities and identity processes in crises: Recommendations for facilitating safe response to the COVID-19 pandemic. British Journal of Social Psychology, 59(3), 674-685. https://doi.org/10. $1111 /$ bjso. 12400

Valsiner, J. (1984). Two alternative epistemological frameworks in psychology: The typological and variational modes of thinking. The Journal of Mind and Behavior, 5(4), 449-470. Retrieved from http:// www.jstor.org/stable/43853057

Valsiner, J. (2017). From methodology to methods in human psychology. Springer International Publishing.

Van Bavel, J. J., Baicker, K., Boggio, P. S., Capraro, V., Cichocka, A., Cikara, M., \& Drury, J. (2020). Using social and behavioural science to support COVID-19 pandemic response. Nature Human Behaviour, 4, 460-471. https://doi.org/10.1038/s41562-0200884-z

Walsh, F. (2020). Loss and resilience in the time of COVID-19: Meaning making, hope, and transcendence. Family Process, 59(3), 898-911. https://doi.org/10.1111/famp.12588

Warner-Søderholm, G. (2012). Culture matters: Norwegian cultural identity within a Scandinavian context. SAGE Open, 2(4), 1-12. https://doi.org/10.1177/2158244012471350

Xiong, J., Lipsitz, O., Nasri, F., Lui, L. M., Gill, H., Phan, L., \& McIntyre, R. S. (2020). Impact of COVID19 pandemic on mental health in the general population: A systematic review. Journal of Affective Disorders, 277, 55-64. https://doi.org/10.1016/j.jad.2020.08.001

Yang, F. (2021). Coping strategies, cyberbullying behaviors, and depression among Chinese netizens during the COVID-19 pandemic: a web-based nationwide survey. Journal of Affective Disorders, 281, 138-144. https://doi.org/10.1016/j.jad.2020.12.023

Young, N. A., Waugh, C. E., Minton, A. R., Charles, S. T., Haase, C. M., \& Mikels, J. A. (2020). Reactive, agentic, apathetic, or challenged? Aging, emotion, and coping during the COVID-19 Pandemic. The Gerontologisd. https://doi.org/10.1093/geront/gnaa196

Zimmer-Gembeck, M. J., \& Skinner, E. A. (2011). The development of coping across childhood and adolescence: An integrative review and critique of research. International Journal of Behavioral Development, 35(1), 1-17.

Publisher's Note Springer Nature remains neutral with regard to jurisdictional claims in published maps and institutional affiliations. 